\title{
Climate Change Effects On Height-Diameter Allometric Relationship Vary With Tree Species And Size For Larch Plantations In Northern And Northeastern China
}

\section{Qigang Xu}

Chinese Academy of Forestry https://orcid.org/0000-0003-0984-1781

Xiangdong Lei ( $\nabla$ xdlei@ifrit.ac.cn )

Chinese Academy of Forestry

Hao Zang

Jiangxi Agriculture University

Weisheng Zeng

State Forestry and Grassland Administration

\section{Research}

Keywords: nonlinear mixed-effects model, height-diameter model, climate change, climate-sensitive growth model

Posted Date: November 23rd, 2021

DOI: https://doi.org/10.21203/rs.3.rs-1081902/v1

License: (c) (i) This work is licensed under a Creative Commons Attribution 4.0 International License. Read Full License

Version of Record: A version of this preprint was published at Forests on March 17th, 2022. See the published version at https://doi.org/10.3390/f13030468. 

species and size for larch plantations in northern and northeastern China

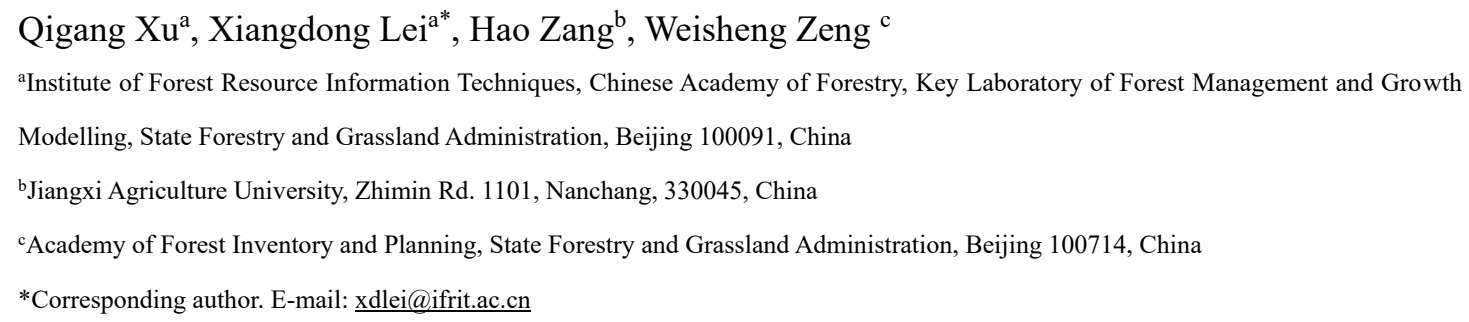

\section{Abstract:}

Background: Tree height-diameter relationship is very important in forest investigation, understanding forest ecosystem structure and estimating carbon storage. Climate change may modify the relationship. However, our understanding of the effects of climate change on height-diameter allometric growth is still limited at large scale.

Methods: In this study, we explore how the climate change effects on height-diameter allometric relationship vary with tree species and size for larch plantations in northern and northeastern China. Based on the repeated measurement data of 535 plots from the 6th to 8th national forest inventory of China, climate-sensitive tree height-diameter models of Larix plantations in north and northeast China were developed by two-level nonlinear mixed effect (NLME) method. The final model was used to analyze the height-diameter relationship of different Larch species under RCP2.6, RCP 4.5, and RCP8.5 climate change scenarios from 2010 to 2100.

Results: The values of $R_{a d j}^{2}$ (adjusted coefficient of determination), MAE(mean absolute error) and RMSE(root mean squared error) of the NLME models for calibration data were $0.92,0.76 \mathrm{~m}$ and $1.06 \mathrm{~m}$, respectively. The inclusion of climate variables MAT (Mean annual temperature), CMD (Hargreaves climatic moisture deficit) with random effects was able to increase $R_{a d j}^{2}$ by $19.5 \%$ and reduce the AIC (Akaike's information criterion), MAE and RMSE by $22.2 \%, 44.5 \%$ and $41.8 \%$, respectively. The climate sensitivity was ranked as $L$. gmelinii $>$ the unidentified species group $>$ L. pincipis-rupprechtii $>$ L. kaempferi $>$ L. olgensis under RCP4.5, but L. gmelinii $>$ L. pincipis-rupprechtii $>$ the unidentified species group > L. olgensis > L. kaempferi under RCP2.6 and RCP8.5. 
Conclusion: According to the climate sensitivity, tree species could be classified as group I (L. gmelinii, L. pincipis-rupprechtii and the unidentified species group) with large $\Delta H$ (from $-4.77 \%$ to $18.17 \%$ ) and group II (L. kaempferi and L. olgensis) with small $\Delta H$ (from -6.37\% to 9.4\%).Large trees were more sensitive to climate change than small trees.

Key words: nonlinear mixed-effects model; height-diameter model; climate change; climate-sensitive growth model

\section{Background}

Tree height-diameter (H-D) models are one of the most useful tools in forest management. Because tree height measurement is time-consuming, expensive and difficult in over-crowed and dense forests, a small number of trees are typically subsampled in practice to measure tree height, while D is measured precisely for all trees in a plot (Zell 2018). Thus, H-D models are often constructed to predict missing total height measurements for the rest of the trees. Numerous H-D models have been developed (Fang and Bailey 1998; Huang, Price et al. 2000; Jayaraman and Zakrzewski 2001; Calama and Montero 2004; Sharma and Yin Zhang 2004; Sharma and Parton 2007; Kroon, Andersson et al. 2008; Hulshof, Swenson et al. 2015; Zang, Lei et al. 2016; Zell 2018; Zhang, Chhin et al. 2019; Bronisz and Mehtätalo 2020; Ciceu, Garcia-Duro et al. 2020; Santiago-García, Jacinto-Salinas et al. 2020; Zhang, Sajjad et al. 2020). Models showed that the H-D relationship was context-dependent, and dependent on genetic characteristics (Kroon, Andersson et al. 2008), stand age (Sánchez, Varela et al. 2003), site condition (Sharma and Yin Zhang 2004; Sharma and Parton 2007; Krisnawati, Wang et al. 2010; Zhang, Sajjad et al. 2020), competition status (Calama and Montero 2004; Sharma and Yin Zhang 2004; Sharma and Parton 2007; Ciceu, Garcia-Duro et al. 2020), silvicultural treatment (Saunders and Wagner 2008; Russell, Amateis et al. 2010) and climate (Wang, Fang et al. 2006; Hulshof, Swenson et al. 2015; Fortin, Van Couwenberghe et al. 2019; Zhang, Chhin et al. 2019).

Under the background of global change, the effects of climate change on forest growth were attained great concerns (Hasenauer, Nemani et al. 1999; Kirschbaum 2000; Yang, Watanabe et al. 2006; HartlMeier, Dittmar et al. 2014; Charney, Babst et al. 2016). However, how climate change alerts H-D relationships has only recently been considered (Albert and Schmidt 2010; Hulshof, Swenson et al. 2015; 
Fortin, Van Couwenberghe et al. 2019; Zhang, Chhin et al. 2019; Ng'andwe, Chungu et al. 2021). For example, Hulshof, Swenson et al. (2015) developed mixed-effects models to test H-D allometric differences due to climate and functional groups, and models showed that temperature, and some extent precipitation, in part explained tree allometric variation. Climate variables can significantly explain the variation of the relationship between tree height and diameter, and adding climate variables can improve the prediction practicability of the model in the context of climate change. Zhang, Chhin et al. (2019) developed tree level NLME model to explore height-diameter allometry of Chinese fir in relation to climate and found that temperature was a key climate factor shaping height-diameter allometry, and showed that tree heights increased with increasing mean annual temperature. Fortin, Van Couwenberghe et al. (2019) developed generalized H-D models of 44 tree species across France and found that the temperature effect was significant for 33 species and the precipitation effect was significant only for 7 species. They estimated that two-thirds of climate sensitive species are expected to be generally shorter under RCP2.6 scenario.

However, the direction and magnitude of climatic effects on H-D relationships has further exploration space. For example, Hulshof, Swenson et al. (2015) showed that the coefficient of MAT was negative but the model developed by Zhang, Chhin et al. (2019) showed MAT has positive effects on H-D allometry. Feldpausch, Banin et al. (2011) found that annual precipitation coefficient of variation, dry season length, and mean annual air temperature were key drivers of variation in H-D allometry at the pantropical and region scales. Ng'andwe, Chungu et al. (2021) found that temperature negatively modulate H-D allometry in Pinus merkusii and P. michoacana in Zambia. Furthermore, how these climatic effects differ among tree species and sizes of Larch are not well understood. The climate effects on H-D relationship are likely to have an impact on tree stability, height estimation, yield prediction and forest management decision, thus making it necessary to examine it under climate change.

Larch is an economically and ecologically important genus of tree species in China, especially in the northern and northeastern Provinces. The area and volume of larch forests in Chinese forests amount to 6.50 and 6.77 per cent, respectively (State Forestry Administration 2014). Both empirical and processbased models found that future climate change would affect stand growth, productivity, and biological rotation of larch plantations (Shen, Lei et al. 2015; Lei, Yu et al. 2016; Zang, Lei et al. 2016; Xie, Wang et al. 2017; Xie, Lei et al. 2020), but how climate change will modify the H-D relationship is unknown yet. Therefore, the objectives of the study were: 1) to develop a climate-sensitive H-D model for larch 
plantations in north and northeast China; 2) to examine the effects of future climate change on H-D relationship among larch species and tree sizes. Quantifying the effects of climate change will help better understand the H-D allometric relationship and adaptive forest management under climate change.

\section{Methods}

\section{Tree height-diameter Data}

Tree H-D data used in this study were from $6^{\text {th }}$ (year 2000), $7^{\text {th }}$ (year 2005)and $8^{\text {th }}$ (year 2010) National Forest Inventories in 7 provinces (Beijing, Hebei, Shanxi, Liaoning, Jilin, Heilongjiang, and Inner Mongolia) in north and northeast China. We selected only pure larch plantation plots to develop the H-D model. The larch species presented in these plots are L. gmelinii., L. olgensis, L. kaempferi, L. principis-rupprechtii. In addition, there were trees are not identified to specific species which were recorded as larch. According to the protocol of NFI, heights of 3-5 medium trees were measured in each plot. In total, 7304 pairs of H-D measurements in 535 plots were obtained across seven Provinces. Data were split into two parts for model calibration and validation by the following method: each plot was randomly allocated to a number between 1 and 535, and plots whose number were less than 20th percentile of all plots were assigned as validation data (1609 pairs in 107 plots) and the rest were fitting data (5695 pairs of H-D measurements in 428 plots). Summary statistics of tree and stand variables can be found in Table 1. The scatter plot can be found in Figure 1.

(



Table 1 Summary statistics for tree and stand variables by Provinces

\begin{tabular}{|c|c|c|c|c|c|c|c|c|}
\hline Data & Province & $\begin{array}{l}\text { Number } \\
\text { of Plots }\end{array}$ & $\begin{array}{l}\text { Number } \\
\text { of tree } \\
\text { observat } \\
\text { ions }\end{array}$ & $\begin{array}{c}\mathrm{D} \\
(\mathrm{cm})\end{array}$ & $\begin{array}{c}\mathrm{H} \\
(\mathrm{m})\end{array}$ & $\begin{array}{l}\text { AGE } \\
\text { (a) }\end{array}$ & $\begin{array}{c}\mathrm{N} \\
\left(\text { trees }^{\bullet} \mathrm{ha}^{-1}\right)\end{array}$ & $\begin{array}{c}\text { BA } \\
\left(\mathrm{m}^{2} \bullet \mathrm{ha}^{-1}\right)\end{array}$ \\
\hline \multirow{8}{*}{$\begin{array}{l}\text { Calibr } \\
\text { ation }\end{array}$} & Beijing & 7 & 37 & $14.7(4.6)$ & $9.3(2.3)$ & $32.9(10.6)$ & $561.9(418.5)$ & $9.1(9.9)$ \\
\hline & Hebei & 72 & 3326 & $10.7(4.5)$ & $7.9(2.2)$ & $21.7(6.7)$ & $1072.6(540.9)$ & $9.3(7.3)$ \\
\hline & Heilongjiang & 96 & 706 & $14.5(5.3)$ & $13(3.9)$ & $27.9(9.7)$ & $653.9(520.5)$ & $4.6(4.6)$ \\
\hline & Jilin & 132 & 1058 & $12.9(4.7)$ & $11.4(4.4)$ & $25.2(9.9)$ & $1032.2(565.3)$ & $9.0(5.6)$ \\
\hline & Liaoning & 52 & 406 & $14.4(4.8)$ & $13.5(4.5)$ & $23.6(10.2)$ & $1292.3(631.7)$ & $13.5(8.6)$ \\
\hline & $\begin{array}{c}\text { Inner } \\
\text { Mongolia }\end{array}$ & 35 & 188 & $12.2(3.7)$ & $10.1(3.2)$ & $25.8(7.1)$ & $855.1(617.7)$ & $8.0(6.4)$ \\
\hline & Shanxi & 34 & 195 & $11.1(3.1)$ & $8.7(2.8)$ & $26.5(9.3)$ & $1297.8(627.3)$ & $9.4(7.7)$ \\
\hline & total & 428 & 5916 & $11.9(4.8)$ & $9.6(3.8)$ & $23.6(8.5)$ & $977.2(610.6)$ & $8.5(6.9)$ \\
\hline \multirow{8}{*}{$\begin{array}{l}\text { Valida } \\
\text { tion }\end{array}$} & Beijing & 3 & 18 & $12.6(1.7)$ & $9.2(1.6)$ & $25.8(3.1)$ & $816.8(469.2)$ & $11.5(10.7)$ \\
\hline & Hebei & 12 & 620 & $11.4(3.8)$ & $8.9(2.3)$ & $24.8(7.6)$ & $994.9(607.2)$ & $8.5(5.4)$ \\
\hline & Heilongjiang & 27 & 193 & $15.2(5.0)$ & $13.1(3.8)$ & $29.5(9.8)$ & $559.3(548.7)$ & $6.0(6.3)$ \\
\hline & Jilin & 38 & 351 & $13.5(4.4)$ & $11.9(4.0)$ & $28.4(11.1)$ & $904.2(532.9)$ & $8.2(4.9)$ \\
\hline & Liaoning & 12 & 97 & $12.2(4.5)$ & $11.3(5.4)$ & $23.2(9.3)$ & $1207.8(651.1)$ & $17.7(7.0)$ \\
\hline & $\begin{array}{c}\text { Inner } \\
\text { Mongolia }\end{array}$ & 11 & 53 & 11.1(4.4) & $9.1(4.1)$ & $28(9.9)$ & $1135.5(835.4)$ & $7.3(6.4)$ \\
\hline & Shanxi & 4 & 21 & $9(1.8)$ & $6.7(2.0)$ & $17.9(4.2)$ & $848.6(622.8)$ & $7.3(6.3)$ \\
\hline & total & 107 & 1353 & $12.5(4.4)$ & $10.4(3.8)$ & $26.3(9.4)$ & $902.6(626.8)$ & $8.6(6.8)$ \\
\hline
\end{tabular}

120 Note: D, diameter at breast height; H, tree height; $N$, tree number per hectare; BA, basal area per hectare;

121 the numbers within parentheses are the standard deviation.

122

Figure 1 Scatter plot of tree height-diameter allometry by Larch species in 7 provinces.

\section{Climate data}

125 The current climatic data for model calibration were downloaded from ClimateAP, which is an application for dynamic local downscaling of historical and future climate data in Asia Pacific (Wang,

127 Wang et al. 2017). Seasonal and annual climate variables (averaged from 1980 to 2010) for a plot were produced based on latitude, longitude, and elevation (Table 2). 
Table 2. Descriptions of the candidate climatic variables

\begin{tabular}{cl}
\hline Variable & \\
\hline AHM & Annual heat:moisture index \\
CMD & Hargreaves climatic moisture deficit \\
DD_0 & Degree-days below $0{ }^{\circ} \mathrm{C}$ \\
DD_18 & Degree-days below $18^{\circ} \mathrm{C}$ \\
DD18 & Degree-days above $18^{\circ} \mathrm{C}$ \\
DD5 & Degree-days above $5^{\circ} \mathrm{C}$ \\
EMT $/{ }^{\circ} \mathrm{C}$ & Extreme minimum temperature over a 30-year period \\
EXT $/{ }^{\circ} \mathrm{C}$ & Extreme maximum temperature over a 30-year period \\
EREF & Hargreaves reference evaporation \\
MAP $/$ mm & Mean annual precipitation (mm) \\
MAT / ${ }^{\circ} \mathrm{C}$ & Mean annual temperature \\
MCMT / ${ }^{\circ} \mathrm{C}$ & Mean coldest month temperature \\
MWMT / ${ }^{\circ} \mathrm{C}$ & Mean warmest month temperature \\
NFFD & The number of frost-free days \\
PAS $/ \mathrm{mm}$ & Precipitation as snow between August in previous year and July \\
in current year $/{ }^{\circ} \mathrm{C}$ & Temperature difference between MWMT and MCMT, or \\
& continentality \\
\hline
\end{tabular}

For projections of future H-D relationship under expected climate change, we used the latest climate-

131 change scenarios of the $5^{\text {th }}$ Assessment Report from the IPCC using a downscaled global climate model 132 (GCM) applied in three representative concentration pathways (RCPs), RCP2.6, RCP4.5, and RCP8.5 133 (Van Vuuren, Edmonds et al. 2011). These pathways represent the scenarios with low, medium and high concentrations of greenhouse gases and predictive radiative forcing. The GCM model for future climate scenarios used in the study was CNRM-CM5 (The Centre National de Recherches Météorologiques Coupled global climate Model) (Voldoire, Sanchez-Gomez et al. 2013). Future climate data for the time periods 2025 (average for 2010-2040), 2055 (average for 2040-2070) and 2085 (average for 2070-2100) were also downloaded from the ClimateAP. 

for evaluation of the climatic variability and can be robust as an auxiliary technique when used in combination with other statistical techniques (Scolforo, Maestri et al. 2013). We first used PCA method to analyze the data for all climate variables. Owing to climate variables with different units, all variables were standardized prior to PCA. Components explaining more than $80 \%$ of the variance were retained. For each component, variables with large loading were selected for further analysis. These variables with strong correlations with $\mathrm{H}$ and the least multicollinearity among them were served as options for modelling.

\section{Basic H-D models}

152

The basic H-D model was from Zang et al. (2016) for the same tree species in the region and modified as Eq. (1) which was a generalized H-D model with the inclusion of competition effects besides tree diameter.

$$
H=1.3+\left(a_{0}+a_{1} B A L\right) \times\left(1-\exp \left(-\left(b_{0}+b_{1} B A L\right) \times D\right)\right)^{c}+\varepsilon
$$

Where $H$ is the total tree height (m), $D$ is the diameter at breast height (cm), BAL is the sum of basal area larger than a subject tree, $a_{0}, a_{1}, b_{0}, b_{1}$ and $c$ are model parameters, which have their own biological characteristics, and $\varepsilon$ is random error.

To evaluate the differences in height-diameter allometry among larch species, dummy variables $S_{m}$ were created: (1) $S_{1}=1$ denotes the L. gmelinii. and 0 the rest of cases; (2) $S_{2}=1$ denotes the $L$. olgensis and 0 the rest of cases; (3) $S_{3}=1$ denotes the L. principis-rupprechtii. and 0 the rest of cases; (4) $S_{4}=1$ denotes the L. kaempferi; and (5) the category which can not be identified was represent by $S_{1}=S_{2}=S_{3}=S_{4}=0$ as the reference.

Therefore, the model could be written as:

$$
H=f\left(\beta, S_{m}, D, B A L\right)+\varepsilon
$$

Where $\beta$ is the fixed-effect parameter vector, $S_{m}$ was dummy variable denoting tree species, and other variables are defined as above. 
To quantify the climatic effects on the H-D allometry, the selected climate variables were added into the model by reparameterization for parameters in basic H-D model, and it could be written as:

$$
H=f\left(\beta, B A L, \text { Climate, } S_{m}, D\right)+\varepsilon
$$

Where Climate was the climate variable vector selected by PCA and correlation analysis, and other variables were the same as mentioned above.

Owing to the correlated H-D observations in plots violating the principle of independence of error terms and the strong predictive ability of mixed effects model in forestry data (Calama and Montero 2004; Sharma and Parton 2007), the nonlinear mixed effected model can be an appropriate way to develop the climate sensitive H-D model which can be written as:

$$
\begin{aligned}
& H_{i j k}=f\left(\beta, D_{i j k}, B A L, \text { Climate }, S_{m}, u_{i}, u_{i j}\right)+\varepsilon_{i j k} \\
& u_{i} \sim N\left(0, \sigma_{\text {province }}^{2}\right), u_{i j} \sim N\left(0, \sigma_{\text {plot }}^{2}\right) .
\end{aligned}
$$

Where $H_{i j k}$ and $D_{i j k}$ is the $k^{\text {th }}$ individual tree height nested within $j^{\text {th }}$ plot in the $i^{\text {th }}$ province, $u_{i}$ and $u_{i j}$ is the province- and plot-level random effects, and $\varepsilon_{i j k}$ is the random error. Other variables were the same as mentioned above.

The estimated random effect parameter $\boldsymbol{u}_{\boldsymbol{i}}$ were calculated as follows:

$$
\widehat{\boldsymbol{u}}_{i}=\widehat{\boldsymbol{\Psi}} \widehat{Z}_{i}^{T}\left(\widehat{\boldsymbol{Z}}_{i} \widehat{\Psi}_{\bar{Z}}^{T}+\widehat{R}_{i}\right)^{-1} e_{i}
$$

$$
\text { Where } \widehat{\boldsymbol{u}}_{\boldsymbol{i}} \text { is the estimated prediction vector for random parameters, } \widehat{\boldsymbol{\Psi}} \text { is the estimated } \mathrm{q} \times \mathrm{q}
$$
variance-covariance matrix for among-unit variability, where $\mathrm{q}$ is the number of random effects parameters in the model, $\widehat{\boldsymbol{R}}_{\boldsymbol{i}}$ is the estimated $\mathrm{k} \times \mathrm{k}$ variance-covariance matrix for within-unit variability, $\widehat{\boldsymbol{Z}}_{\boldsymbol{i}}$ is the partial derivatives matrix with respect to the random parameters and $\boldsymbol{e}_{\boldsymbol{i}}$ is the residual vector determined by the difference between the observed and predicted heights using model which only has fixed effects.

To account for the within-unit heteroscedasticity and autocorrelation in variance-covariance matrix $\left(\boldsymbol{R}_{\boldsymbol{i}}\right)$, the variance-covariance matrix was determined as:

$$
\boldsymbol{R}_{\boldsymbol{i}}=\sigma^{2} \boldsymbol{G}_{\boldsymbol{i}}^{0.5} \Gamma_{i} \boldsymbol{G}_{\boldsymbol{i}}^{0.5}
$$

Where $\sigma^{2}$ is the value of residual variance of the estimated model, $\boldsymbol{G}_{\boldsymbol{i}}$ is a diagonal matrix explaining the variance of within unit heteroscedasticity, $\Gamma_{\boldsymbol{i}}$ is a diagonal matrix accounting for within tree autocorrelation structure of errors, and AR(1) was used to reflect the within-tree autocorrelation 
structure of errors for matrix $\Gamma_{i}$. To reduce the heterogeneity in variance, the variance power equation was determined as:

$$
\operatorname{var}\left(\varepsilon_{i j k}\right)=\sigma^{2} \widehat{H}_{i j k}^{2 \gamma}
$$

where, $\widehat{H}_{i j k}$ is the estimated height of $k^{\text {th }}$ tree nested in $j^{\text {th }}$ plot in $i^{\text {th }}$ province using fixed part of the mixed-effects model; $\gamma$ is the parameter to be estimated; and $\sigma^{2}$ is the same as defined in Eq.6. Parameters in NLME models were estimated by restricted maximum likelihood implemented with 'nlme' package in R software (Pinheiro, Bates et al. 2013).

When a new subject is available(for example, the one in the validation set), the model needs to be calibrated for this subject by using information about the subject to estimate the empirical best linear unbiased predictors (EBLUPs) of the random effects parameters (Meng and Huang 2009). The methods from Gordan was reference to compose the predict function in R (Nigh 2012; Team 2013).

\section{Model evaluation and validation}

The following statistics were employed for model evaluation and validation: the adjusted coefficient of determination $\left(R_{a d j}^{2}\right)$, Akaike's information criterion (AIC), the mean absolute error (Scolforo, Maestri et al.), the root mean square error (RMSE).

$$
\begin{aligned}
& R_{a d j}^{2}=1-\frac{\sum_{i=1}^{n_{i}} \Sigma_{j=1}^{n_{i j}} \sum_{k=1}^{n_{i j k}}\left(H_{i j k}-\widehat{H}_{i j k}\right)^{2}}{\sum_{i=1}^{n_{i}} \sum_{j=1}^{n_{i j}} \sum_{k=1}^{n_{i j k}}\left(H_{i j k}-\bar{H}\right)^{2}} \times \frac{n-1}{n-p-1} \\
& M A E=\frac{\sum_{i=1}^{n_{i}} \Sigma_{j=1}^{n_{i j}} \Sigma_{k=1}^{n_{i j k}}\left|H_{i j k}-\widehat{H}_{i j k}\right|}{n}
\end{aligned}
$$

$$
R M S E=\sqrt{\frac{\sum_{i=1}^{n_{i}} \Sigma_{j=1}^{n_{i j}} \Sigma_{k=1}^{n_{i j k}}\left(H_{i j k}-\widehat{H}_{i j k}\right)^{2}}{n}}
$$

$$
A I C=-2 \log L i k+2 k
$$

Where $\mathrm{n}$ is the number of observations, $\widehat{H}_{i j k}$ is $k^{\text {th }}$ tree estimated height of nested in $j^{\text {th }}$ plot nested in $i^{\text {th }}$ province ; $H_{i j k}$ is the $k^{\text {th }}$ tree observed height nested in $j^{\text {th }}$ plot nested in $i^{\text {th }}$ province. $\bar{H}$ is the observed mean height for all data, $n_{i}, n_{i j}, n_{i j k}$ are the total number of the province, the plots nested in $i^{\text {th }}$ province, $k^{\text {th }}$ trees nested in the $j^{\text {th }}$ plot nested in $i^{\text {th }}$ province, $p$ is the number of model parameters; and $L L$ is the log-likelihood. 
For each plot, we produced 37 simulated trees with diameter from $5 \mathrm{~cm}$ (minimum value of D in calibration data) to $41 \mathrm{~cm}$ (maximum value of $\mathrm{D}$ in calibration data), and these diameter values were set to be evenly distributed. The values of BAL were obtained by mean value of each D with interval of $1 \mathrm{~cm}$ in calibration data. According to final nlme model with the inclusion of climate variables, tree heights for a given D of all plots under different climate change scenarios were predicted. After the corresponding $\mathrm{H}$ of each $\mathrm{D}$ is averaged, the H-D curves of different larch species under climate change scenarios were generated. For observe how the climate change effect the H-D allometry in details, the relative change of tree height $\triangle \mathrm{H}$ was defined for comparisons with a given $\mathrm{D}$ (Eq. 12). Similarly, after the corresponding $\triangle H$ of each $D$ is averaged, the $\triangle H$-D curves of different larch species were generated.

$$
\triangle \mathrm{H}=\sum_{1}^{n}\left(H_{\text {change }}-H_{\text {current }}\right) / \mathrm{n} \times H_{\text {current }}
$$

Where $\mathrm{n}$ was the number of simulated trees. $H_{\text {change }}$ and $H_{\text {current }}$ represent tree height value predicted under future and current climate scenarios, respectively.

\section{Results}

\section{Selected climate variables}

Three principal components described $95.27 \%$ of the variability of the climate data (Table 3 ). For component 1 , the variables with absolute loading values $>0.3$ were MAT, DD_0, DD5, DD_18 and NFFD, so the component 1 mainly represents the temperature variability. For component 2, the variables which absolute loading values $>0.3$ were TD, MAP, AHM and CMD, so the component 2 represents the moisture variability. For component 3, TD and PAS were chosen.

According to the loading, the most two important climate variables were selected which include MAT, DD_18, CMD, MAP, TD, PAS. Table 4 presents the correlation between these climate variables and tree height. Because of the collinearity between MAT, DD_18, MAP, TD and PAS. Finally, only MAT and CMD were selected for further reparameterization using NLME. Summary statistics of MAT and CMD can be found in Table 5 . 
Table 3 PCA analysis result of the climate variables

\begin{tabular}{lrrr}
\hline & Comp.1 & Comp.2 & Comp.3 \\
\hline MAT & 0.331 & 0.000 & 0.000 \\
MWMT & 0.265 & 0.248 & -0.229 \\
MCMT & 0.282 & -0.172 & 0.272 \\
TD & -0.114 & 0.341 & -0.43 \\
MAP & 0.000 & 0.394 & 0.338 \\
AHM & 0.147 & -0.387 & -0.262 \\
DD_0 & -0.302 & 0.104 & -0.238 \\
DD5 & 0.301 & 0.185 & -0.14 \\
DD_18 & -0.329 & 0.000 & -0.104 \\
DD18 & 0.269 & 0.243 & -0.183 \\
NFFD & 0.311 & 0.150 & 0.000 \\
PAS & -0.172 & 0.265 & 0.388 \\
EMT & 0.287 & -0.128 & 0.21 \\
EXT & 0.250 & 0.171 & -0.357 \\
Eref & 0.249 & -0.215 & 0.000 \\
CMD & 0.000 & -0.444 & -0.238 \\
Accumulated variance & 56.050 & 81.680 & 95.27 \\
\hline
\end{tabular}

Table 4 Pearson correlation coefficient matrix between $\mathrm{H}$ and climatic variables

\begin{tabular}{lrrrrrrr}
\hline Variables & \multicolumn{1}{l}{ CMD } & TD & PAS & MAP & DD_18 & MAT & H \\
\hline CMD & 1.000 & - & - & - & - & - & - \\
TD & $-0.424^{* * *}$ & 1.000 & - & - & - & - & - \\
PAS & $-0.673^{* * *}$ & $0.193^{* * *}$ & 1.000 & - & - & - & - \\
MAP & $-0.841^{* * *}$ & $0.141^{* * *}$ & $0.566^{* * *}$ & 1.000 & - & - & - \\
DD_18 & $-0.041^{* * *}$ & $0.435^{* * *}$ & $0.421^{* * *}$ & $-0.358^{* * *}$ & 1.000 & - & - \\
MAT & -0.004 & $-0.347^{* * *}$ & $-0.412^{* * *}$ & $0.390^{* * *}$ & $-0.995^{* * *}$ & 1.000 & - \\
H & $-0.503^{* * *}$ & $0.404^{* * *}$ & $0.329^{* * *}$ & $0.414^{* * *}$ & $0.070^{* * *}$ & $-0.029^{* * *}$ & 1.000 \\
\hline
\end{tabular}

Note: ${ }^{*}, \mathrm{p}<0.05 ;^{* *}, \mathrm{p}<0.01 ;^{* * *}, \mathrm{p}<0.001$.

Table 5 Mean value of MAT and CMD under 3 climate change scenarios

\begin{tabular}{llll}
\hline MAT & Period:2010-2040 & Period:2040-2070 & Period:2070-2100 \\
\hline RCP2.6 & $3.95(2.40)$ & $4.41(2.41)$ & $4.53(2.43)$ \\
RCP4.5 & $3.92(2.43)$ & $4.87(2.44)$ & $5.70(2.42)$ \\
RCP8.5 & $4.14(2.42)$ & $5.69(2.42)$ & $7.44(2.36)$ \\
\hline CMD & Period:2010-2040 & Period:2040-2070 & Period:2070-2100 \\
\hline RCP2.6 & $180.96(88.22)$ & $164.38(75.68)$ & $164.34(87.09)$ \\
RCP4.5 & $158.82(82.30)$ & $142.16(77.02)$ & $180.26(83.53)$ \\
RCP8.5 & $160.62(83.16)$ & $186.03(82.88)$ & $187.04(82.78)$ \\
\hline
\end{tabular}


When climate variables were selected into the model, all the explanatory variables were determined.

Then, we tested all the combinations of dummy variables representing different species, climate variables and Province- and plot- level random effects to parameters from the basic model (Eq. 1). The final model with good convergence and the lowest AIC value was chosen for simulations. The climate variables were set into parameter $a$ and $b$, the tree species dummy variables and random effects were set into parameter a.

Therefore, the equations 2 to 4 can be rewritten representing basic H-D model, climate-sensitive H-D model, and climate-sensitive mixed-effect H-D model (Eq. 13-15).

$$
\begin{aligned}
& H_{i j k}=1.3+\left(a_{0}+a_{1} B A L+\sum_{m=1}^{4} f_{m} S_{m}\right)\left[1-e^{b_{0} D_{i j k}+b_{1} B A L}\right]^{c}+\varepsilon_{i j k} \\
& H_{i j k}=1.3+\left(a_{0}+a_{1} \mathrm{BAL}+a_{2} M A T+a_{3} C M D+\sum_{m=1}^{4} f_{m} S_{m}\right)[1- \\
& \left.e^{\left(b_{0}+b_{1} B A L+b_{2} M A T+b_{3} C M D\right) D_{i j k}}\right]^{c}+\varepsilon_{i j k} \\
& H_{i j k}=1.3+\left(a_{0}+a_{1} \mathrm{BAL}+a_{2} M A T+a_{3} C M D+\sum_{m=1}^{4} f_{m} S_{m}+u_{i}+u_{i j}\right)[1- \\
& \left.e^{\left(b_{0}+b_{1} B A L+b_{2} M A T+b_{3} C M D\right) D_{i j k}}\right]^{c}+\varepsilon_{i j k}
\end{aligned}
$$

Where $f_{1} \sim f_{4}, a_{0} \sim a_{3}, b_{0} \sim b_{3}, c$ are the model parameters to be estimated; other variables are defined as above.

\section{Model comparison and evaluation}

The fitting and validation results of the models are shown in Table 6. The base model (Eq.13) described $76 \%$ part of the variations in the height-diameter relationship when fitted the training data $\left(R_{a d j}^{2}=0.76\right)$. When tree species dummy variable and province-specific, plot-specific random effects were included in the base model, the climate variables contributed significantly to the variance of tree heights and $R_{a d j}^{2}$ increased from 0.77 to 0.92 (Table 6). Training dataset showed similar results, and the inclusion of climate variables (Eq. 14) resulted in the increase $R_{a d j}^{2}$ by $3 \%$ and the reduce of AIC by $3 \%$. Mixed effect model (Eq. 15) also removed the heteroscedasticity of residuals (Figure 2).

\section{Figure 2 Residuals vs predicted values for different H-D models based on calibration data}




\begin{tabular}{llllll}
\hline & $\begin{array}{l}\text { parame } \\
\text { ter }\end{array}$ & $\begin{array}{l}\text { parameter } \\
\text { definition }\end{array}$ & Eq.(13) & Eq. (14) & Eq. (15) \\
\hline $\begin{array}{lllll}\text { fixed-effects } \\
\text { parameters }\end{array}$ & $a_{0}$ & & $21.382(0.000)$ & $21.460(0.000)$ & $19.772(0.000)$ \\
& $b_{0}$ & & $0.078(0.000)$ & $0.088(0.000)$ & $0.106(0.000)$ \\
& $c_{0}$ & & $1.616(0.000)$ & $1.545(0.000)$ & $2.083(0.000)$ \\
& $a_{1}$ & BAL & $-0.137(0.000)$ & $-0.085(0.000)$ & $-0.111(0.000)$ \\
& $a_{2}$ & MAT & & $1.322(0.000)$ & $0.259(0.0381)$ \\
& $a_{3}$ & CMD & & $-0.021(0.000)$ & $-0.030(0.000)$ \\
& $b_{1}$ & BAL & $0.001(0.000)$ & $0.001(0.000)$ & $0.005(0.000)$ \\
& $b_{2}$ & MAT & & $-0.005(0.000)$ & $0.003(0.0024)$ \\
& $b_{3}$ & CMD & & $0.000(0.07)$ & $0.000(0.000)$ \\
& $f_{1}$ & L. gmelinii & $-5.137(0.000)$ & $-3.790(0.000)$ & $0.216(0.898)$ \\
& $f_{2}$ & L. olgensis & $3.234(0.000)$ & $3.317(0.000)$ & $1.879(0.013)$ \\
& $f_{3}$ & L. kaempferi & $-4.944(0.000)$ & $-2.951(0.000)$ & $0.865(0.050)$ \\
& $f_{4}$ & $\begin{array}{l}\text { L. principis- } \\
\text { rupprechtii. }\end{array}$ & $2.557(0.000)$ & $2.319(0.000)$ & $0.226(0.735)$
\end{tabular}

Variance

components

model performance

\section{$\gamma$}

AIC

$\sigma_{p l o t}$

Fitting set $R_{a d j}^{2}$ 23007.83

22368

17911.4

Fitting set $\mathrm{MAE}(\mathrm{m})$ 0.77

0.79 0.92

Fitting set

$\operatorname{RMSE}(\mathrm{m})$

1.28

0.76

Validation set

$\operatorname{MAE}(\mathrm{m})$

1.82

1.72

1.06

Validation set

RMSE(m) the parameter of correlation structure. AIC was the Akaike's information criterion. 
Results showed different effects of climate variables on parameters $a_{0}$ and $b_{0}$, denoting the maximum and relative change of tree height with diameter (Table 6). Parameter $a_{1}$ was significantly negative indicating the increasing BAL will reduce the maximum height. The coefficient $a_{2}$ of MAT for parameter $a$ was significantly positive which means that the rising MAT will increase the maximum tree height. This was also shown in Figure 3 where all H-D curves of different species became steeper under RCP2.6 and RCP 4.5 from 2010 to 2070 . However, parameter $b_{2}$ was negative indicating that the rising MAT will lower the tree height with the same diameter and there is a threshold for the effect of temperature on $\mathrm{H}$ D relationship of larch species. Parameter $a_{3}$ was significantly negative indicating the decreasing precipitation will reduce the maximum height. Both CMD and BAL showed marginal effects on H-D relationship since $b_{1}$ and $b_{3}$ were nearly zero.

Table 6 showed that all parameters of tree species dummy variables $f_{l} \sim f_{4}$ were positive, but $f_{l}$ and $f_{4}$ were not significant, indicating that L.olgensis and L.Kaempfer had significant difference with unidentified group, which was also illustrated in Figure. 3. Coefficient $f_{2}$ was the largest indicating that the maximum of tree height is the largest for L.olgensis.

MAT increases with the time and the temperature under RCP8.5 is largest followed by RCP4.5 and $\mathrm{RCP}$ 2.6. The precipitation under RCP8.5 is smallest and has the steepest slope followed by RCP4.5 and RCP2.6. Figure 4 showed the $\Delta \mathrm{H}-\mathrm{D}$ curve of larch species under climate scenarios RCP2.6, RCP4.5 and kaempferi and L. olgensis ). They showed strong ( $\Delta \mathrm{H}$ from $-4.77 \%$ to $18.17 \%)$ and weak $(\Delta \mathrm{H}$ from $6.37 \%$ to $9.40 \%$ ) responses to climate change, respectively. The values of $\Delta \mathrm{H}$ for Group I were positive which indicated that future climate change increased tree height compared with current climate with the exception of RCP 2.6 from 2010 to 2040 and RCP8.5 from 2040-2100. However, the values of $\Delta \mathrm{H}$ were complicated varying from negative to positive with the increasing diameter for Group II. but there were different responses to climate among larch species. For tree species group I, the $\Delta \mathrm{H}$ increased with the increase of tree DBH in small and medium sizes and kept stable in large size. For group II, the absolute $\Delta \mathrm{H}$ increased with the increase of tree $\mathrm{DBH}$, but changed from negative to positive 

scenarios in period 2010 to 2100 (mean value of the absolute $\Delta \mathrm{H}$ in period 2010 to 2040,2040 to 2070 and 2070 to 2100 ) was shown in Figure 5. It can be observed that the climate sensitivity of larch species was ranked as L. gmelinii $>$ L. pincipis-rupprechtii $>$ the unidentified species group $>$ L. olgensis $>$ L. kaempferi under RCP2.6 and RCP8.5, and the sensivity was larger under RCP8.5 than that under RCP2.6. However, the sensitivity was ranked as L. gmelinii $>$ the unidentified species group $>$ L. pincipisrupprechtii $>$ L. kaempferi $>$ L. olgensis under RCP4.5.

Figure 3 Relationship between tree height and DBH of larch species under different climate change scenarios

Figure 4 Relative change of tree height with diameter among larch species under different climate scenarios

\section{Discussion} model with the inclusion of climate variables provided better performance compared to fixed-effects model without climate variables, which could also be found in other reports (Sharma and Parton 2007; by $19.5 \%$ and reduce the AIC, MAE and RMSE by $22.2 \%, 44.5 \%$ and $41.8 \%$ for fitting set, respectively. Zang, Lei et al. 2016; Zhang, Chhin et al. 2019; Bronisz and Mehtätalo 2020; Ciceu, Garcia-Duro et al. 2020). In this study, using mixed-effects model and including climate variables was able to increase $R_{a d j}^{2}$ The residual heterogeneity was also reduced. Owing to the correlation among tree height-diameter observations, fixed-effect model would lead to biased variance of the parameter estimates and thus invalidate the hypothesis tests (Pinheiro, Bates et al. 2013). Mixed effect modelling approach can be an appropriate solution to this problem (Calama and Montero 2004; Sharma, Vacek et al. 2016). Similarly, 
Vizcaíno-Palomar, Ibáñez et al. (2017) reported that inclusion of climate variables and random effects reduce the AIC by 9.0\%. Sharma, Vacek et al. (2016) reported that inclusion of random effects was able to increase the $R_{a d j}^{2}$ by $9.2 \%$ and reduce the AIC and RMSE by $7.8 \%$ and $25 \%$, respectively.

The climate variables including MAT and CMD significantly affected H-D relationship but the effect was not very strong which was in line with the previous studies (Hulshof, Swenson et al. 2015; Fortin, Van Couwenberghe et al. 2019; Zhang, Chhin et al. 2019).Temperature usually affects the growth season and growth rate of tree height. Low temperature will hinder the division and specialization of cambium and meristem cells, thus accumulating more nutrients and carbohydrates and distributing them to the trunk, therefore the shape of tree changed (Kilpeläinen, Peltola et al. 2006). Fortin, Van Couwenberghe et al. (2019) pointed out that the mean temperature from March to September affected H-D relationship of most French species. Temperature was not a marginal effect that can be overlooked and its effect was also quadratic so that an optimal temperature existed. Ng'andwe, Chungu et al. (2021) also found that increasing temperature beyond the optimum for Pinus merkusii and P. michoacana will reduce the tree growth and increase the rotation age. Similarly, in this study, MAT modified parameters $a_{2}$ and $b_{2}$ positively and negatively, respectively, which also indicated that there was an optimal temperature for larch tree height. Zhang, Chhin et al. (2019) reported that MAT was the dominant climatic factor in modulating height-diameter allometry of Chinese fir, and the effect of MAT and MWMT were positively associated with tree height. Larch in the region begins to grow in May, and the growth speed reaches the maximum in July, then gradually slows down until it stops growing (Wang, Wang et al. 1992). Therefore, the temperature in May and the precipitation in the previous year are very important for the height growth of larch. Our results showed that CMD had significant effects on H-D relationship. The coefficient of $\mathrm{CMD}, a_{3}$, was negative which indicated that the height decreases with the increase of water deficiency. This was consistent with previous study (Zhou, Lei et al. 2019) which found that the precipitation from the previous October to the current April significantly promoted the height growth of Mongolian pine. Sang, Sebastian - Azcona et al. (2019) also found that the negative and positive effects of CMD on the height of white spruce trees in northern Canada.

Besides climate, H-D relationship was affected by multiple biotic and abiotic variables, for example genetic characteristics (Kroon et al., 2008), stand age (Sánchez et al., 2003), site condition (Sharma and Yin Zhang, 2004; Sharma and Parton, 2007; Zhang et al., 2020), competition status (Calama and Montero, 2004; Sharma and Yin Zhang, Ciceu et al., 2020). Considering the inclusion of other stand factors will 
aggravate the model complexity, we only use diameter and BAL as the independent variable for ensuring more stable convergence. Other methods like machine learning were worthy of further exploration in future study.

\section{The impact of climate change on H-D relationship by larch species and tree size}

Our model simulations showed that the effects of climate change on H-D relationship varied with larch species. Generally, $\Delta \mathrm{H}-\mathrm{D}$ curves of larch species can be obviously classified as two groups, which are group I (L. gmelinii group, L. pincipis-rupprechtii group and the unidentified species group) and group II (L. kaempferi and L. olgensis). They showed strong ( $\Delta \mathrm{H}$ from $-4.77 \%$ to $18.17 \%)$ and weak $(\Delta \mathrm{H}$ from $-6.37 \%$ to $9.40 \%$ ) response to future climate change, respectively. Under warmer and drier climatic conditions, L.kaempferi and L.ogensis will grow thicker and shorter than the rest of the tree species group, and their $\Delta \mathrm{Hs}$ are lower than those of group I for a given tree diameter. This may due to these two tree species are moisture loving species (Wang et al., 1992). Under drought stress, the hydraulic conductivity of the xylem of the trunk suffers irreversible loss. Therefore, the lack of water during the growing season allows to allocate more resources for the growth of diameter (Ryan and Yoder 1997). Compared with group II, group I is more resistant. As the temperature increases, more resources will be allocated to the growth of the height than the diameter, thus trees would be higher. Previous studies also supported this result (Aiba and Kitayama 1999; THORNLEY 1999; Schelhaas 2008; Zhang, Wang et al. 2020).

$\Delta \mathrm{H}$ also varied with tree diameter under future climate change. For tree species group I, $\Delta \mathrm{H}$ increased for small and medium sizes and kept stable for large sizes. This may be resulted from the limited height growth of trees with large diameter because of the limits to tree height (Koch, Sillett et al. 2004). For tree species group II, $\Delta \mathrm{H}$ increased with the increasing $\mathrm{DBH}$, but changed from negative to positive, indicating that small trees will grow short but large trees high. Campbell, Magnussen et al. (2021) reported that large trees were most sensitive to annual climate fluctuations. From the perspective of competition, larger trees in a stand have more competitive advantages than smaller trees while the smaller neighbor trees do not influence the growth of larger trees (Cannell et al., 1984). Under the warmer and drier climate in the future, due to the developed root system of the big trees, their growth will not be affected by the lack of water, and the growth of small trees may face drought stress. McDowell, Pockman et al. (2008) pointed out that plants can avoid water damage caused by drought through stomatal closure, 
leading to carbon starvation and a cascade of down-stream effects. Seedlings or small trees are more likely to inhibit growth or even die due to hydraulic failure. The phenomena of changing from negative to positive for $\Delta \mathrm{H}$ of $L$. kaempferi and L. olgensis along with increasing diameter support this conclusion.

\section{Conclusions}

Two-level climate-sensitive NLME model was developed for larch planatations in north and northeast China in this study which showed biological and statistical reasonability. MAT, CMD, was the dominant climatic factor in modulating height-diameter allometry of larch plantations. Model simulation showed that the climate sensitivity of H-D allometry varied with tree species and diameter. According to the climate sensitivity, tree species could be classified as group I(L. gmelinii, L. pincipis-rupprechtii and the unidentified species group) with large $\Delta H$ (from $-4.77 \%$ to $18.17 \%$ ) and group II (L. kaempferi and $L$. olgensis) with small $\Delta H$ (from $-6.37 \%$ to $9.4 \%$ ). Large trees were more sensitive to climate change than small trees.

\section{Declarations}

\section{Ethics approval and consent to participate}

The authors declare that the study was not conducted on endangered, vulnerable or threatened species. The authors declare that they obtained the informed consent from human participants involved in this study.

\section{Consent for publication}

All authors gave their informed consent to this publication and its content.

\section{Funding}

This study was funded by National Natural Science Foundation of China (Grant No. 31870623).

\section{Availability of data and material}

The datasets generated during and/or analysed during the current study are available from the 
corresponding author on reasonable request.

427

\section{Authors' contributions}

Q.G. Xu: Data preparation, Data analysis, Writing, review \& editing; X. D. Lei: Conceptualisation,

Funding, Writing, review \& editing; H. Zeng and W. S. Zeng: Data collection, review \& editing.

\section{Competing interests}

The authors declared that they have no conflicts of interest to this work.

\section{Acknowledgements}

None.

References

Aiba S-i, K Kitayama (1999) Structure, composition and species diversity in an altitude-substrate matrix of rain forest tree communities on Mount Kinabalu, Borneo. Plant Ecology 140:139-157

Albert M, M Schmidt (2010) Climate-sensitive modelling of site-productivity relationships for Norway spruce (Picea abies (L.) Karst.) and common beech (Fagus sylvatica L.). Forest Ecology and Management 259:739-749

Bronisz K, L Mehtätalo (2020) Mixed-effects generalized height-diameter model for young silver birch stands on post-agricultural lands. Forest Ecology and Management 460:117901

Calama R, G Montero (2004) Interregional nonlinear height diameter model with random coefficients for stone pine in Spain. Canadian Journal of Forest Research 34:150-163

Campbell EM, S Magnussen, JA Antos, R Parish (2021) Size-, species-, and site-specific tree growth responses to climate variability in old-growth subalpine forests. Ecosphere 12:e03529

Charney ND, F Babst, B Poulter, S Record, VM Trouet, D Frank, BJ Enquist, ME Evans (2016) Observed forest sensitivity to climate implies large changes in 21st century North American forest growth. Ecology letters 19:1119-1128

Ciceu A, J Garcia-Duro, I Seceleanu, O Badea (2020) A generalized nonlinear mixed-effects heightdiameter model for Norway spruce in mixed-uneven aged stands. Forest Ecology and Management 477:118507

Fang Z, R Bailey (1998) Height-diameter models for tropical forests on Hainan Island in southern China. Forest Ecology and Management 110:315-327

Feldpausch TR, L Banin, OL Phillips, TR Baker, SL Lewis, CA Quesada, K Affum-Baffoe, EJ Arets, NJ Berry, M Bird (2011) Height-diameter allometry of tropical forest trees. Biogeosciences 8:10811106

Fortin M, R Van Couwenberghe, V Perez, C Piedallu (2019) Evidence of climate effects on the heightdiameter relationships of tree species. Annals of Forest Science 76:1 
Hartl-Meier C, C Dittmar, C Zang, A Rothe (2014) Mountain forest growth response to climate change in the Northern Limestone Alps. Trees 28:819-829

Hasenauer H, RR Nemani, K Schadauer, SWJFe Running, management (1999) Forest growth response to changing climate between 1961 and 1990 in Austria. Forest ecology and management 122:209-219

Huang S, D Price, SJ Titus (2000) Development of ecoregion-based height-diameter models for white spruce in boreal forests. Forest Ecology and Management 129:125-141

Hulshof CM, NG Swenson, MD Weiser (2015) Tree height-diameter allometry across the United States. Ecology and evolution 5:1193-1204

Jayaraman K, W Zakrzewski (2001) Practical approaches to calibrating height-diameter relationships for natural sugar maple stands in Ontario. Forest Ecology and Management 148:169-177

Kilpeläinen A, H Peltola, I Rouvinen, S Kellomäki (2006) Dynamics of daily height growth in Scots pine trees at elevated temperature and CO 2. Trees 20:16-27

Kirschbaum MU (2000) Forest growth and species distribution in a changing climate. Tree physiology 20:309-322

Koch GW, SC Sillett, GM Jennings, SD Davis (2004) The limits to tree height. Nature 428:851-854

Krisnawati H, Y Wang, PK Ades (2010) Generalized height-diameter models for Acacia mangium Willd. plantations in south Sumatra. Indonesian Journal of Forestry Research 7:1-19

Kroon J, B Andersson, TJ Mullin (2008) Genetic variation in the diameter-height relationship in Scots pine (Pinus sylvestris). Canadian journal of forest research 38:1493-1503

Lei X, L Yu, L Hong (2016) Climate-sensitive integrated stand growth model (CS-ISGM) of Changbai larch (Larix olgensis) plantations. Forest Ecology and Management 376:265-275

McDowell N, WT Pockman, CD Allen, DD Breshears, N Cobb, T Kolb, J Plaut, J Sperry, A West, DG Williams (2008) Mechanisms of plant survival and mortality during drought: why do some plants survive while others succumb to drought? New phytologist 178:719-739

Meng SX, S Huang (2009) Improved calibration of nonlinear mixed-effects models demonstrated on a height growth function. Forest science 55:238-248

Ng'andwe P, D Chungu, F Tailoka (2021) Stand characteristics and climate modulate height to diameter relationship in Pinus merkusii and P. michoacana in Zambia. Agricultural and Forest Meteorology 307:108510

Nigh G (2012) Calculating empirical best linear unbiased predictors (EBLUPs) for nonlinear mixed effects models in Excel/Solver. The Forestry Chronicle 88:340-344

Pinheiro J, D Bates, S DebRoy, D Sarkar, RC Team (2013) nlme: Linear and nonlinear mixed effects models. R package version 3:111

Russell MB, RL Amateis, HE Burkhart (2010) Implementing regional locale and thinning response in the loblolly pine height-diameter relationship. Southern Journal of Applied Forestry 34:21-27

Ryan MG, B Yoder (1997) Hydraulic limits to tree height and tree growth. Bioscience 47:235-242

Sánchez CAL, JG Varela, FC Dorado, AR Alboreca, RR Soalleiro, JGÁ González, FS Rodríguez (2003) A height-diameter model for Pinus radiata D. Don in Galicia (Northwest Spain). Annals of forest science 60:237-245

Sang Z, J Sebastian-Azcona, A Hamann, A Menzel, U Hacke (2019) Adaptive limitations of white spruce populations to drought imply vulnerability to climate change in its western range. Evolutionary applications 12:1850-1860

Santiago-García W, AH Jacinto-Salinas, G Rodríguez-Ortiz, A Nava-Nava, E Santiago-García, G 
Ángeles-Pérez, JR Enríquez-del Valle (2020) Generalized height-diameter models for five pine species at Southern Mexico. Forest Science and Technology 16:49-55

Saunders MR, RG Wagner (2008) Height-diameter models with random coefficients and site variables for tree species of Central Maine. Annals of Forest Science 65:1-10

Schelhaas M (2008) The wind stability of different silvicultural systems for Douglas-fir in the Netherlands: a model-based approach. Forestry 81:399-414

Scolforo JRS, R Maestri, AC Ferraz Filho, JM de Mello, AD de Oliveira, ALJJJoFR de Assis (2013) Dominant height model for site classification of Eucalyptus grandis incorporating climatic variables. 2013

Sharma M, J Parton (2007) Height-diameter equations for boreal tree species in Ontario using a mixedeffects modeling approach. Forest Ecology and Management 249:187-198

Sharma M, S Yin Zhang (2004) Height-diameter models using stand characteristics for Pinus banksiana and Picea mariana. Scandinavian Journal of Forest Research 19:442-451

Sharma R, Z Vacek, S Vacek (2016) Nonlinear mixed effect height-diameter model for mixed species forests in the central part of the Czech Republic. Journal of Forest Science 62:470-484

Shen C, X Lei, H Liu, L Wang, W Liang (2015) Potential impacts of regional climate change on site productivity of Larix olgensis plantations in northeast China. iForest-Biogeosciences and Forestry 8:642

State Forestry Administration TPsRoC (2014) National Forest Resources Statistics (2009-2013), State Forestry Administration, Beijing, China

Team RC (2013) R: A language and environment for statistical computing.

THORNLEY JH (1999) Modelling stem height and diameter growth in plants. Annals of Botany 84:195205

Van Vuuren DP, J Edmonds, M Kainuma, K Riahi, A Thomson, K Hibbard, GC Hurtt, T Kram, V Krey, J-F Lamarque (2011) The representative concentration pathways: an overview. Climatic change 109:5

Vizcaíno-Palomar N, I Ibáñez, M Benito-Garzón, SC González-Martínez, MA Zavala, R Alía (2017) Climate and population origin shape pine tree height-diameter allometry. New Forests 48:363379

Voldoire A, E Sanchez-Gomez, DS y Mélia, B Decharme, C Cassou, S Sénési, S Valcke, I Beau, A Alias, M Chevallier (2013) The CNRM-CM5. 1 global climate model: description and basic evaluation. Climate dynamics 40:2091-2121

Wang T, G Wang, JL Innes, B Seely, B Chen (2017) ClimateAP: An application for dynamic local downscaling of historical and future climate data in Asia Pacific. Front Agric Sci Eng 458

Wang X, J Fang, Z Tang, B Zhu (2006) Climatic control of primary forest structure and DBH-height allometry in Northeast China. Forest ecology and management 234:264-274

Wang z, S Wang, G Wang, C Wang, t Bai, h Lu, H Lv, C Chen, J Yuan, Z Xu, S Zhang, S Zhang, Y Yang, Q Zeng, J Huang, y Tan, Z Tan (1992) Larch forest in China, China Forestry Publishing House, Beijing

Wold S, K Esbensen, P Geladi (1987) Principal component analysis. Chemometrics and intelligent laboratory systems 2:37-52

Xie Y, X Lei, J Shi (2020) Impacts of climate change on biological rotation of Larix olgensis plantations for timber production and carbon storage in northeast China using the 3-PGmix model. Ecological Modelling 435:109267 
Xie Y, H Wang, X Lei (2017) Application of the 3-PG model to predict growth of Larix olgensis plantations in northeastern China. Forest Ecology and Management 406:208-218

Yang Y, M Watanabe, F Li, J Zhang, W Zhang, J Zhai (2006) Factors affecting forest growth and possible effects of climate change in the Taihang Mountains, northern China. Forestry: An International Journal of Forest Research 79:135-147

Zang H, X Lei, W Zeng (2016) Height-diameter equations for larch plantations in northern and northeastern China: a comparison of the mixed-effects, quantile regression and generalized additive models. Forestry: An International Journal of Forest Research 89:434-445

Zell J (2018) SwissStandSim: A climate sensitive single tree stand simulator for Switzerland: Schlussbericht im Forschungsprogramm Wald und Klimawandel. ETH Zurich

Zhang B, S Sajjad, K Chen, L Zhou, Y Zhang, KK Yong, Y Sun (2020) Predicting Tree Height-Diameter Relationship from Relative Competition Levels Using Quantile Regression Models for Chinese Fir (Cunninghamia lanceolata) in Fujian Province, China. Forests 11:183

Zhang X, S Chhin, L Fu, L Lu, A Duan, J Zhang (2019) Climate-sensitive tree height-diameter allometry for Chinese fir in southern China. Forestry: An International Journal of Forest Research 92:167176

Zhang X, H Wang, S Chhin, J Zhang (2020) Effects of competition, age and climate on tree slenderness of Chinese fir plantations in southern China. Forest Ecology and Management 458:117815

Zhou Y, Z Lei, F Zhou, Y Han, D Yu, Y Zhang (2019) Impact of climate factors on height growth of Pinus sylvestris var. mongolica. PloS one 14:e0213509 
Figures
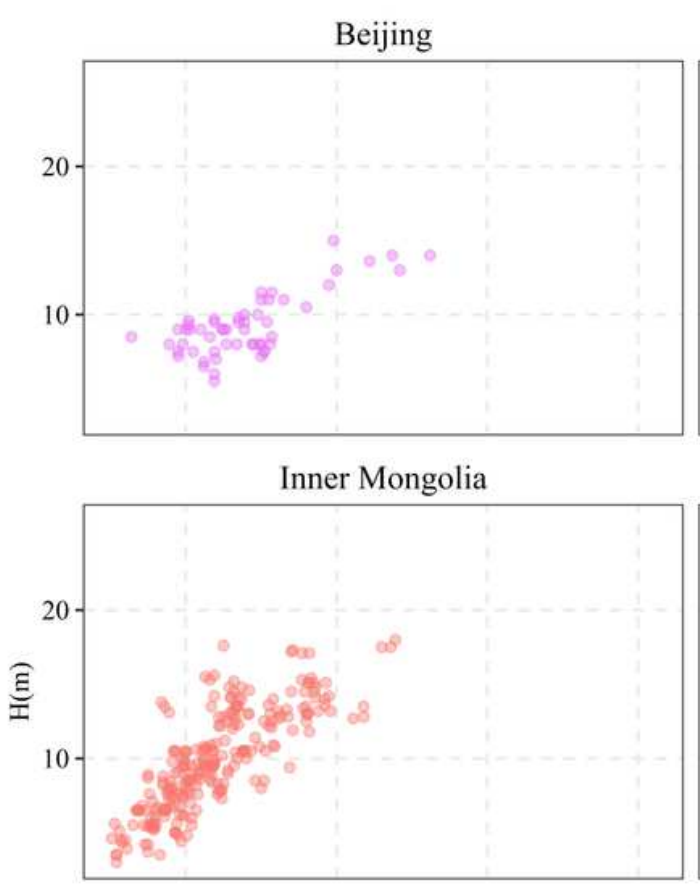

Shanxi

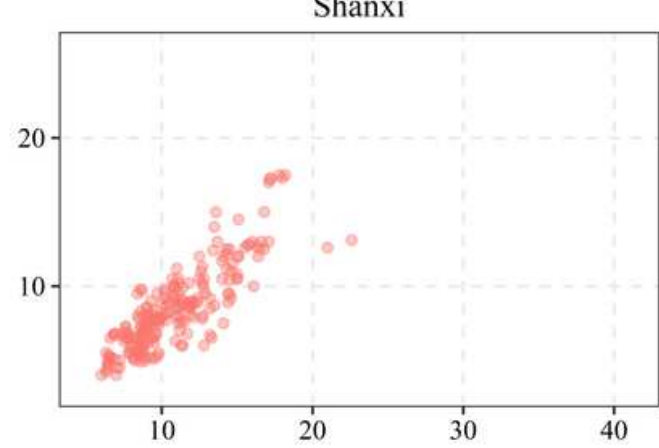

Species - Larch $\circ$ Larix gmelinii(Rupr.)Kuze
Hebei

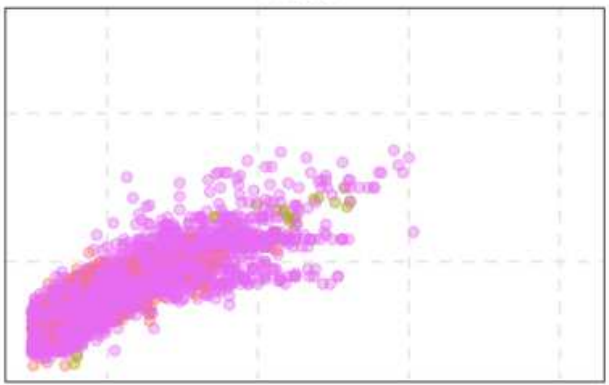

Jilin
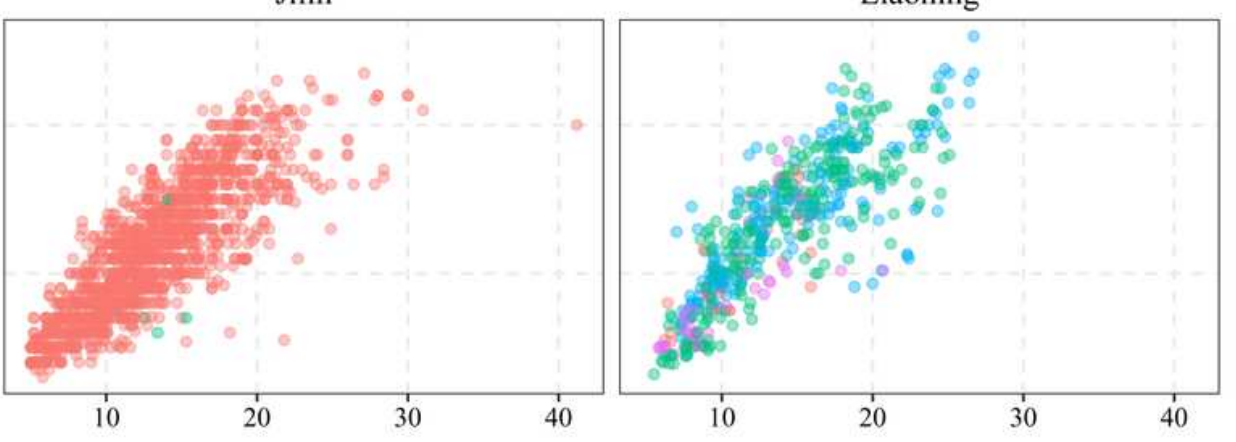

$\mathrm{D}(\mathrm{cm})$

Figure 1

Scatter plot of tree height-diameter allometry by Larch species in 7 provinces. 

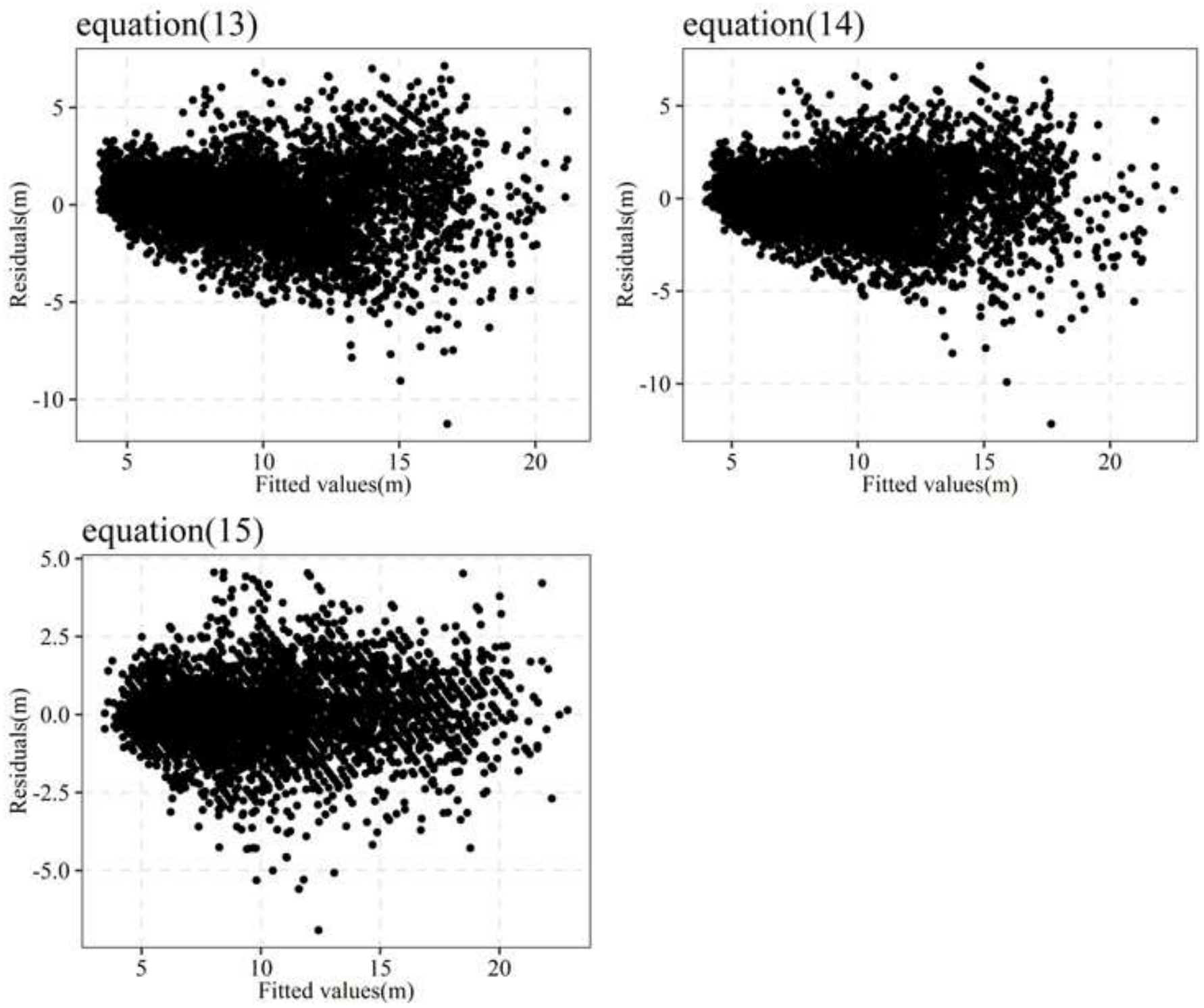

Figure 2

Residuals vs predicted values for different H-D models based on calibration data 

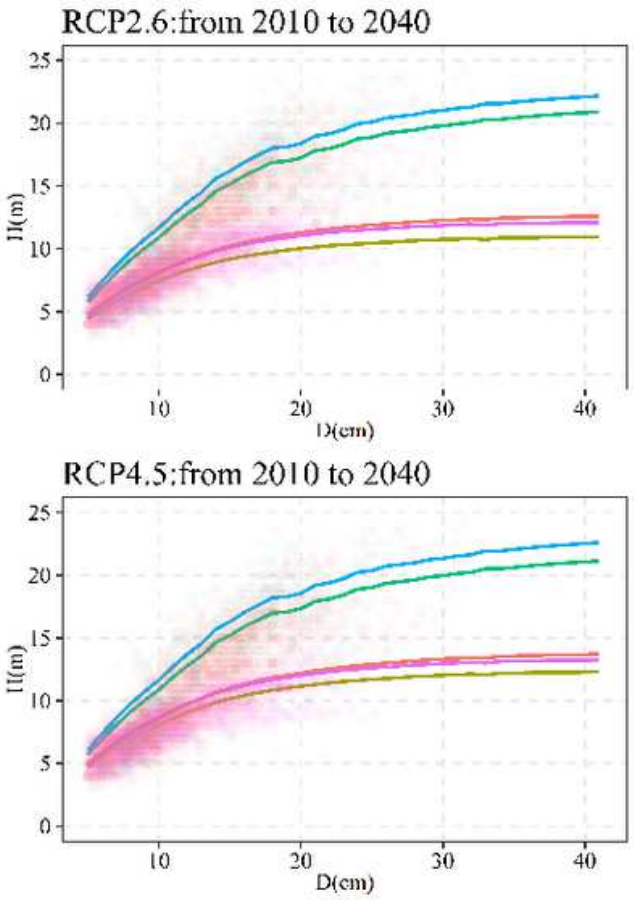

RCP8.5: from 2010 to 2040

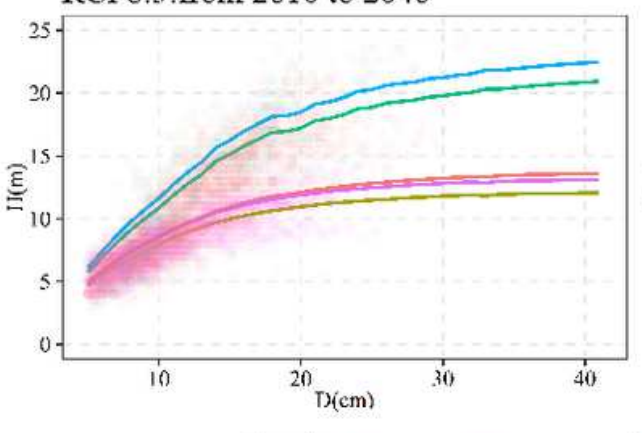

Species - Larch - Larix gmelinii(Rupr.)Kuzen
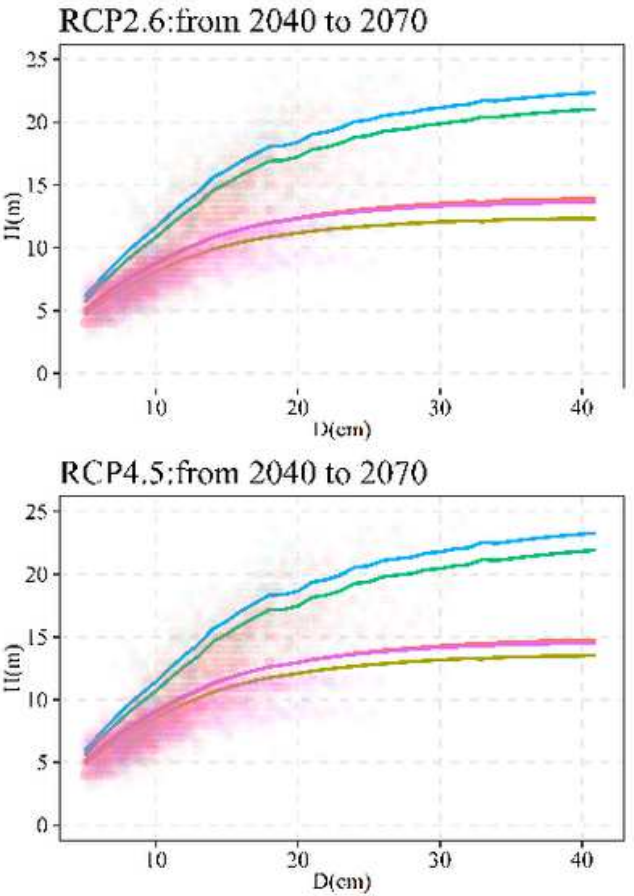

RCP8.5: from 2040 to 2070

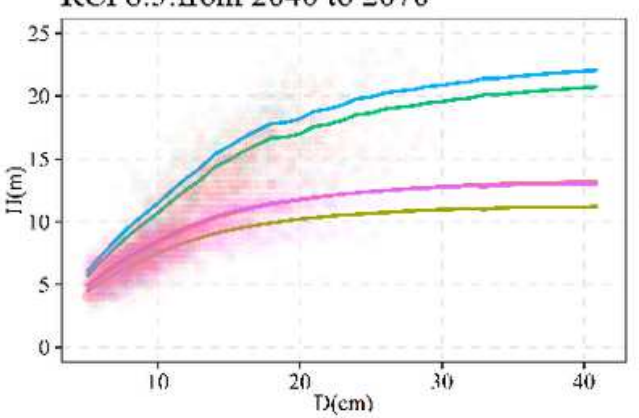

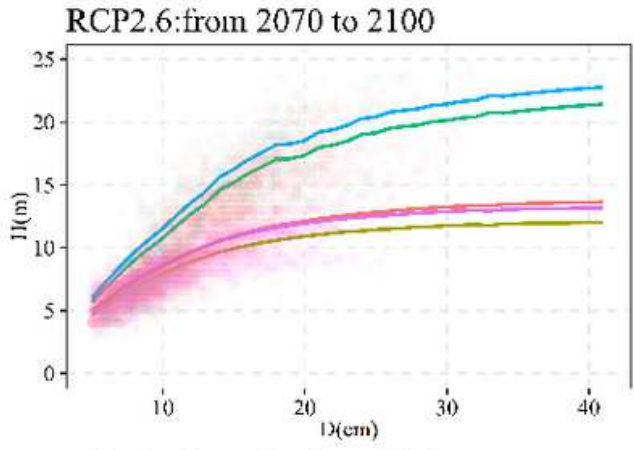

RCP4.5:from 2070 to 2100

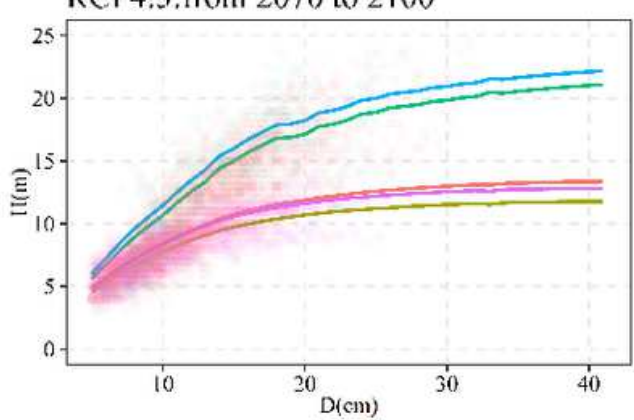

RCP8.5:from 2070 to 2100

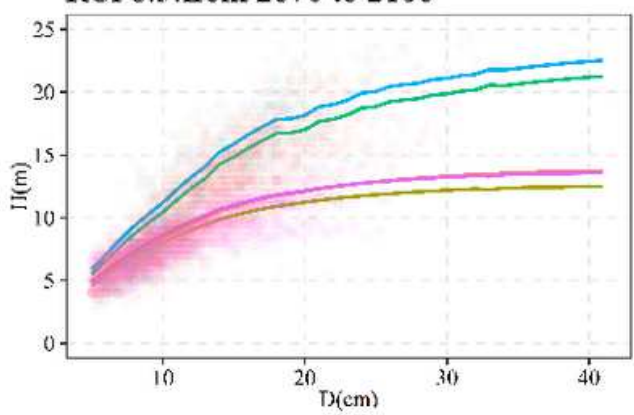

Figure 3

Relationship between tree height and DBH of larch species under different climate change scenarios 


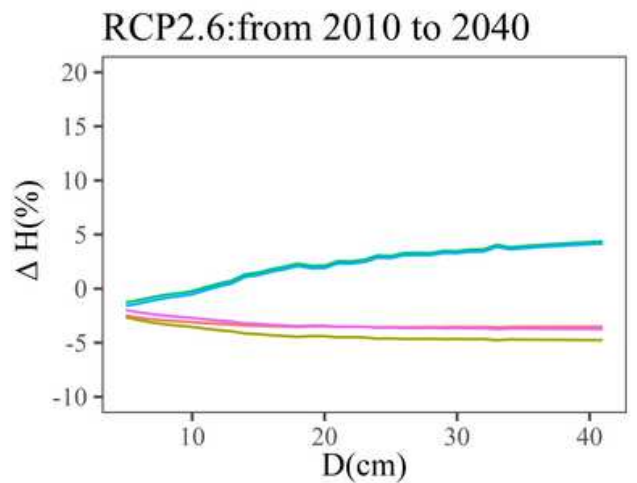

RCP4.5:from 2010 to 2040
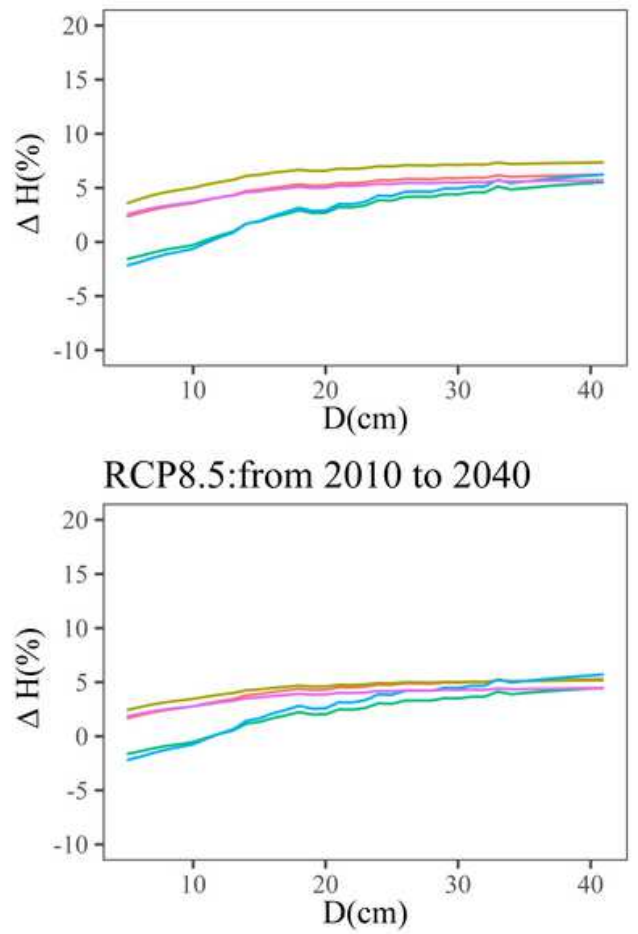

Species — Larch — Larix gmelinii(Rupr.)Kuze

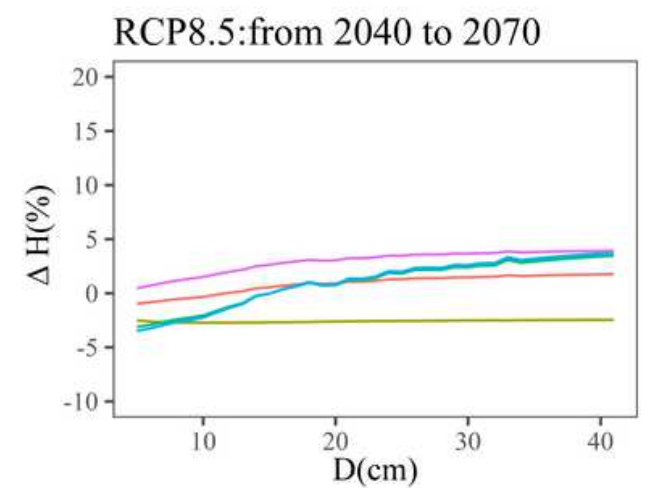

RCP2.6:from 2070 to 2100
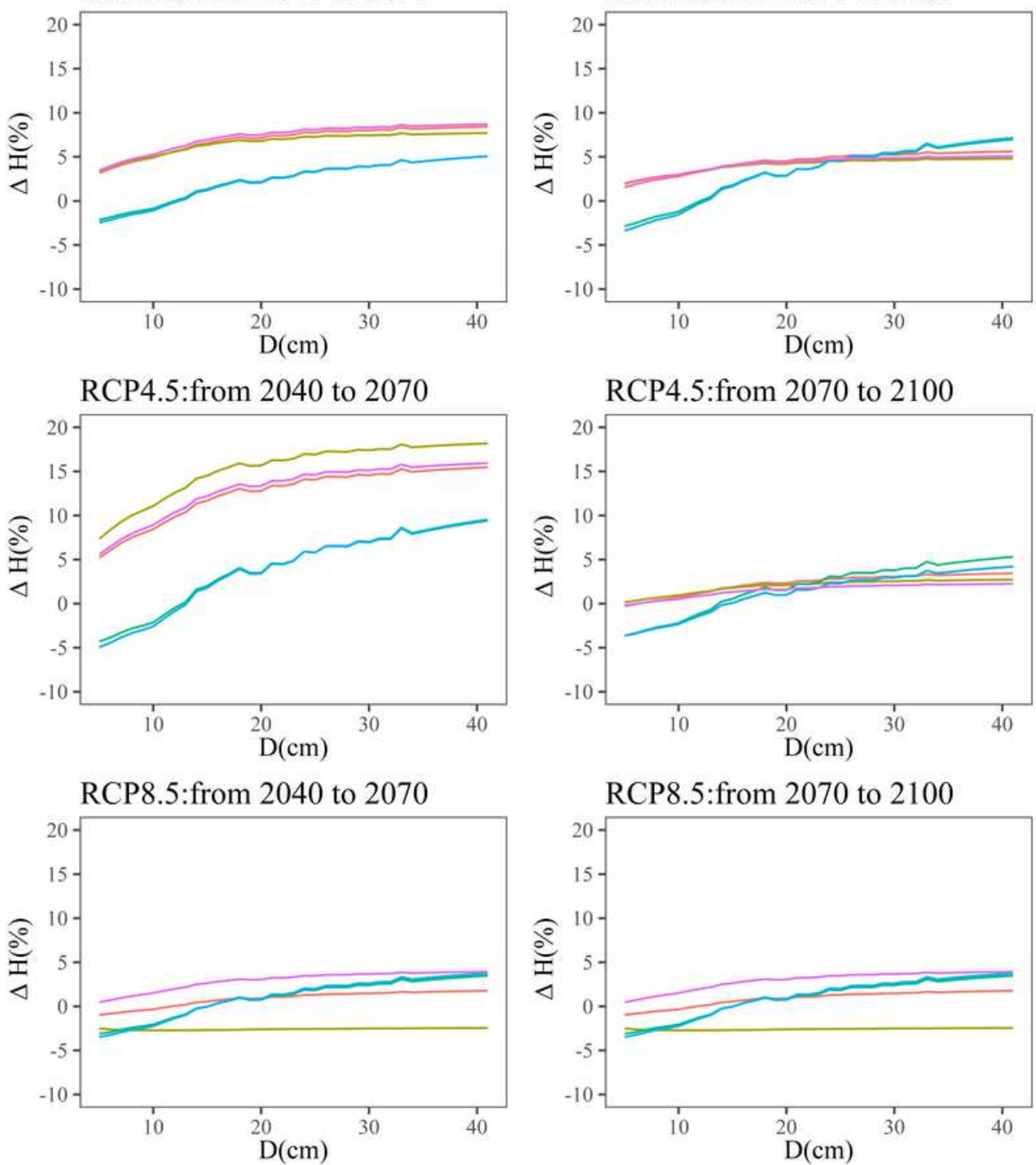

\section{Figure 4}

Relative change of tree height with diameter among larch species under different climate scenarios

\section{Figure 5}

Mean absolute $\Delta \mathrm{H}$ values of height with diameter among larch species under different climate scenarios 